\title{
MONITORING AND SUPPORTING SYSTEM FOR HAZARD MITIGATION
}

\author{
Shih-Chung Huang ${ }^{1}$, Tsung-Min Cheng ${ }^{1}$ and Shih-Hsin Zeng $^{2}$ \\ ${ }^{1}$ Fire Department, Tao-Yuan County, Taiwan, ROC \\ ${ }^{2}$ Research Assistant, Department of Civil Engineering, National Taipei \\ University of Technology, Taipei, Taiwan, ROC
}

\begin{abstract}
Information, communication and controlling technology play important roles in disaster rescues. Referring to the needs of a disaster rescue, this article outlines the structure needed for a Monitoring and Supporting System. It is hoped that such a system will improve the efficiency of the Disaster Command Center and the management of field rescue operations.
\end{abstract}

Keywords: monitoring and supporting system, hazard mitigation, rescue operation

\section{INTRODUCTION}

It is difficult to determine the rescue personnel, vehicles, and equipment needed for the rescue operation when a disaster strikes. It is not uncommon that the search-and-rescue operation failed because of factors such as slowness in reporting the disaster and inadequate dispatching of rescue teams. Therefore, promptly providing the required manpower, equipment, and supplies, and enhancing on-site management of rescue operations are the main responsibilities of the field commander. The commander responding to a disaster needs to exercise proper judgements at the critical moment, and he requires the assistance of the monitoring and supporting system that can provide the most up-todate information, the real-time communications, and the on-site monitoring capability. As an example, this article is based on the seven sub-systems of the current emergency response system of the Tao-Yuan County government - the reporting, the dispatching, the recording, the service management, the graphic file searching, the case management, and the network control sub-systems. It is intended that such a system can be expanded with the communication management system to form an integrated structure of the field rescue command system. It will provide the field commander and the staff at the Disaster Command Center with the best recommendations of rescue strategies. Finally, this article also discusses the needs of a decision-support system to improve the outcomes of the field rescue operations in the disaster area.

\section{THE FRANEWORK OF A MONITORING SYSTEM}

The main purpose of the monitoring system is to obtain the up-to-the-minute reports of a disaster and to monitor the development of a disaster in real time. This will allow the Disaster Command Center to track the late-breaking disaster information with less effort and provide logistic support or on-site recommendations. In addition to the reporting, the dispatching, the recording, the service management, the graphic file searching, the case management, and the network control sub-systems, a monitoring system also includes $[1,2]$ :

1 A graphical positioning sub-system: This subsystem will take the street address of a disaster, and convert it to the longitudinal and latitudinal coordinates. To obtain the field images automatically from the reported disaster site, the field monitoring equipment should have nightvision cameras, the ability to capture images within a $10-\mathrm{km}$ radius, and high resolution zoom lens that can rotate $360^{\circ}$.

2 A communication protocol management subsystem: After the longitudinal and latitudinal coordinates of a disaster are obtained, they will be transmitted by the communication subsystem to the proper field cameras. The cameras will rotate and point to the direction of the disaster automatically.

3 An image transmitting sub-system: The realtime images and video signals can be transmitted by ISDN or radio signals depending on the restrictions of the surrounding landscape.

4 Monitoring software: The monitoring software works in concert with the service dispatching 
system. Whenever a disaster is reported to the county emergency operation center, the report is also forwarded to every rescue unit and to the software monitoring system. After the monitoring system receives the report, it searches relevant information in the central database and displays the location of the disaster on a GIS map. At the same time, the monitoring software also directs the nearest field camera to be rotated to the direction of the disaster and displays the real-time images on the GIS map. This allows the Disaster Command Center to track the on-site conditions of a disaster. To execute the above functions, the software monitoring system should has

4.1 A bulletin board program capable of displaying case information (closed or open), list of open cases, coordinates, graphical locations, and camera information.

4.2 A geographical information system with the case displaying, the inquiring, the address locating, the zooming, and the re-positioning functions.

\section{A DECISION SUPPORT SYSTEM FOR RESCUE OPERATIONS}

Information and timing are the most crucial elements of a successful disaster rescue. To rescue survivors in the shortest time possible requires a considerable amount of accurate information for a field commander to make the proper decisions. A decision support system can promptly provide information on emergency equipment and supplies, track the development of an on-going disaster, and gather the important data quickly. We will address the necessary databases and functions for establishing such a system as follows: $[3,4]$

1 System information requirements: A decision support system for emergency rescue should be able to provide the following information:

1.1 Resource information: Including data on manpower, rescue vehicles, emergency vehicles, ambulances, rescue equipment, emergency supplies, and special rescue forces.

1.2 Household registration information: Including data on local residents, victims, and missing persons.

1.3 Water resource information: Such as reservoirs, fire hydrants, deep-water wells, and rivers.

1.4 Emergency shelter information: Such as available shelters and the accepted residents of the shelters.
1.5 Funeral arrangement information: Such as victims' information, funeral arrangement, and public memorial ceremonies.

1.6 Graphic file management: Including data on buildings, lifelines, and topography.

1.7 Medical facility information: Such as emergency cares, casualty statistics, and post-disaster psychological counseling.

1.8 Lifeline information: Such as gas pipelines, water pipelines, electricity, and telecommunications.

1.9 Logistics information: Emergency supplies such as gasoline, drinking water, food, and camps.

1.10 Civilian rescue force information: Such as volunteers, rescuing organizations, and charitable organizations.

1.11 Disaster information.

1.12 Weather forecasting.

1.13 Specialized personnel information: Such as civil engineers and structural engineers.

2 Functional requirements:

There are five major functional requirementsthe graphical/attribute display, the data editing, the data analysis, the inquiry, and the outputting functions. Among them, the data inquiry function means querying existed databases to obtain relevant information such as household registrations. This is done using the ODBC interfaces to connect to other databases and performing queries via the Structure Query Language (SQL).

3 Software requirements:

3.1 Databases: The most popular databases are the Relational Databases (RDB), the Object-Oriented Databases (OODB), and the Object-Oriented Relational Databases (ORDB). Among them, the ORDB combines the benefits of both RDB and OODB. Since the ORDB stores data as objects, it does not limit itself to a certain file format. Also, the ORDB supports the SQL language to provide better database availability.

3.2 Geographical Information System (GIS): The Geographical Information System can be applied to the field disaster rescues after earthquakes. It gathers information quickly and provides the field commander with detailed information to make better decisions and execution plans. Also, the GIS can provide up-to-the-minute and accurate information and scenes of the disaster to the relatives of the disaster victims, the media, and the government via the Internet. It is indeed an indispensable 
tool for emergency field rescue operations [5]. the Applications of GIS, RS, and GPS on Disaster Mitigation, 1998.

\section{CONCLUSION}

Integrating the emergency dispatching and the automatic self-positioning \& monitoring system can improve the emergency response after a disaster. Also, the integration of the disaster monitoring system and the decision support system is useful to provide more accurate positioning information. As a result, it provides the field rescue commander and the rescue staff at the command center with better support in decision making. However, the application of the integrated system is limited by the restrictions of surrounding buildings, the landscape, the air quality, and the weather conditions. Therefore, the actual deployment of such a system should take all these factors into account. A better result may be achieved under an emergency situation if the surface and the elevated controlling points are combined.

\section{REFERENCE}

[1] Shih, H.-C., "The Study of the Establishment of Urban Disaster Information System-an Application of the Geographic Information System," Graduate Institute of Urban Planning, National Cheng Kung University, Sponsored by the National Science Council, ROC, 1990.

[2] The Project of the Improved Education of Civil Engineering and Disaster Mitigation, The Ministry of Education, The Application of Geographical Information System (GIS) on Disaster Mitigation of Civil Engineering, 1999.

[3] Shih, B.-C., and Jan, L.-C., "The Study of the Application of Information Network System on Urban Disaster Location Management," Proceedings of the Cross-Strait Conference on the Spatial Information and Disaster Mitigation Technologies, 1998.

[4] Chien, C.-M., "The Application of Geographical Information System on the Science of Firefighting," Proceedings of the Cross-Strait Conference on the Applications of GIS, RS, and GPS on Disaster Mitigation, Taipei, pp. 72-99, 1998.

[5] Shih, B.-J., Chen, C.-H., and Wu, K.-C., "The Establishment and Applications of Geographical Information System on Disaster Rescues," Proceedings of the Cross-Strait Conference on 